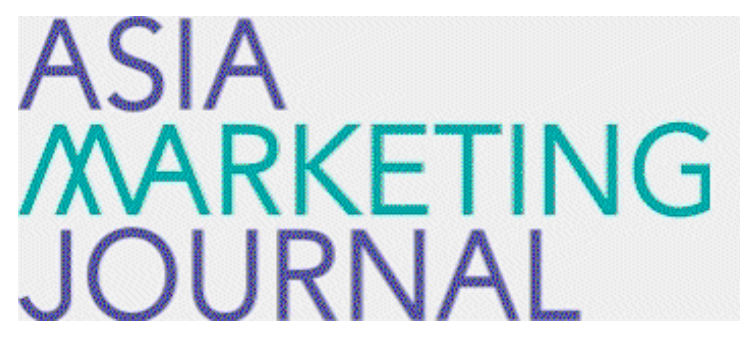

ASIA MARKETING JOURNAL

Volume 13 | Issue 3

Article 8

$10-30-2011$

\title{
공급체인 리더의 관계적 행동이 리더의 리더십과 팔로워의 재무성 과에 미치는 영향
}

Sang Deok Kim

Follow this and additional works at: https://amj.kma.re.kr/journal

Part of the Marketing Commons

\section{Recommended Citation}

Kim, Sang Deok (2011) "공급체인 리더의 관계적 행동이 리더의 리더십과 팔로워의 재무성과에 미치는 영 향," Asia Marketing Journal: Vol. 13 : Iss. 3 , Article 8.

Available at: https://doi.org/10.53728/2765-6500.1292

This Article is brought to you for free and open access by Asia Marketing Journal. It has been accepted for inclusion in Asia Marketing Journal by an authorized editor of Asia Marketing Journal. 


\section{공급체인 리더의 관계적 행동이 리더의 리더십과 팔로워의 재무성과에 미치는 영향: 리더 윤리성의 역할*}

\section{The Effects of Relational Behaviors on Supply Chain Leadership and Financial Performance: \\ The Role of Leader Ethicality}

김 상 덕 $(\mathrm{Kim}$, Sang Deok)**

기존의 리더십과 관련된 연구들은 대부분 조직 내부의 부하와 상사간 관계에 초점을 맞추고 있다. 이는 조직간 거래관계가 기업의 주요한 성패요인이 된 현시점에서 조직 간 리더십에 대한 연구의 필 요성을 제기하는 현상이라 할 수 있다. 특히, 조직 간 거래관계가 분석의 초점인 공급체인 연구에서 는 이러한 조직 간 리더십에 대한 연구가 더욱 필요하다 할 수 있다.

따라서 공급체인의 조직간 리더십을 연구하는 것은 매우 중요하다 할 수 있다. 하지만 기존 공급체 인 리더십 관련 연구들은 두가지 중요한 문제점을 가지고 있다. 첫째, 대부분의 연구들이 공급체인 리더십과 성과 간의 관계에 초점을 맞추고 있다는 점이고, 둘째, 기존 공급체인 내 조직간 리더십 연 구들은 리더십과 재무성과 간 관계를 거의 다루지 않았다는 점이다.

이에 본 연구는 공급체인 리더십의 선행변수를 발견하고, 리더십-성과 간 관계에 영향을 미칠 가능 성이 있는 조절변수를 실증하였다. 특히, 본 연구에서 관심이 있는 공급체인 리더십의 선행변수는 최 근 그 중요성이 강조되고 있는 관계적 행동 변수를, 리더십-성과 간 관계의 조절변수로는 리더의 윤 리성을 검정하였다.

국내 5대 편의점에 상품을 공급하는 공급업체 납품담당자 217 명을 대상으로 설문조사를 실시하였 고, PLS(Partial Least Square) 분석방법을 통해 분석한 결과 대형 유통업체의 관계적 행동 중 교육 훈련, 공정한 보상, 조직간 의사소통은 공급체인 리더십을 강화하였고, 공급체인 리더십은 공급업체의 재무성과를 강화하는 것으로 나타났다. 또한 대형 유통업체의 윤리성이 높은 경우 공급체인 리더십이 공급업체 재무성과를 더 강화시키는 것으로 나타났다. 반면 대형 유통업체의 관계적 행동 중 비전제 시는 공급체인 리더십에 영향을 미치지 않았다.

핵심개념: 관계적 행동, 조직 간 리더십, 재무성과, 리더 윤리성, 공급체인 리더십

본 연구는 2010년도 경남대학교 학술진흥연구비 지원으로 이루어졌음.

** 경남대학교 경영학부 부교수(sdkim@kyungnam.ac.kr) 


\section{I. 서 론}

조직 간에도 리더십이 존재하는가? Morgan (1986)은 조직도 개인들과 마찬가지로 조직의 특성과 관습, 그리고 신념체계를 가진다고 주장 하면서 조직 간 리더십의 중요성을 강조하였으 며, Kime(2001)은 조직 간 리더십의 구체적인 정의를 제시하였다. Kime(2001)에 의하면 조직 간 리더십은 “조직의 위협과 도전, 그리고 기회 가 되는 조직의 내적/외적 자극들에 반응하는 능력”이라고 할 수 있다.

최근 환경 불확실성이 심화되고, 이에 대응하 기 위한 기업간 제휴, 네트워크 조직의 구축이 보편화되면서 이러한 조직 간 리더십에 대한 중요성이 크게 대두되고 있다. 하지만 기존의 리더십과 관련된 연구들은 대부분 조직 내부의 부하와 상사간 관계에 초점을 맞추고 있다. 이 는 조직간 거래관계가 기업의 주요한 성패요인 이 된 현시점에서 조직 간 리더십에 대한 연구 의 필요성을 제기하는 현상이라 할 수 있다.

더욱이, 조직 간 거래관계가 분석의 초점인 공급체인 연구에서는 이러한 조직 간 리더십에 대한 연구가 더욱 필요하다 할 수 있다. 왜냐하 면 공급체인 구성원 간에는 힘의 분배가 균등 하게 이루어질 수 없고(Harrigan 1988), 다수의 구성원 간 시스템적인 관리를 위해서는 리더십이 필수적이기 때문이다(English and Michie 1985, Mehta 2000). 이는 오래전 관련 분야의 중요한 초기연구인 $\operatorname{Etgar}(1977)$ 연구에서부터 주장되 었던 내용이다.

현실적인 측면에서 살펴볼 때도 거의 모든 공 급체인에 리더가 있다. 예를 들어, 대형 제조업
체와 부품 공급업체 간 공급체인에서는 대형 제조업체가, 대형 제조업체와 중소형 유통업체 간 공급체인에서는 대형 제조업체가, 중소 공급 업체와 대형 유통업체 간 공급체인에서는 대형 유통업체가 공급체인 리더라 할 수 있다(오세 조, 박진용, 김상덕 2009).

따라서 공급체인의 조직간 리더십을 연구하는 것은 매우 중요하다 할 수 있다. 하지만 기존 공급체인 리더십 관련 연구들은 중요한 문제점 을 가지고 있다. 첫째, 대부분의 연구들이 공급 체인 리더십과 성과 간의 관계에 초점을 맞추 고 있다. 예를 들어, Schul, Pride, and Little (1983), Price(1993)는 갈등의 감소, Mehta(2000) 는 파트너 동기부여, Hult, Ferrell, Hurley, and Giunipero(2000), 장석인(2009)는 조직결속, Yueh, Lee, and Barnes(2010)는 CRM 이행, Toor and Ofori(2009)는 효과성, 만족, 추가적 역할, 정대용, 이세호(2008)는 만족, 영역초월행동, 재 계약의도, 김상덕(2011)은 조직동일시, 조직시 민행동, 수익성 등의 성과변수와 공급체인 리더 십 간 관계를 연구하였다.

하지만 공급체인 리더십 연구가 업계나 학계 에 현실적인 도움이 되기 위해서는 한계를 가 지고 있다. 예를 들어, "그렇다면 공급체인 리 더가 리더십을 어떻게 가질 수 있는가?” “공급 체인 리더가 리더십을 가지고 있으면 실제로 팔로워의 재무성과가 더 높아지는가?”라는 현 실적인 질문에 대해서는 명확한 답을 제시하기 어렵다.

물론 공급체인 리더십의 선행변수에 관한 연구 가 없었던 것은 아니다. 예를 들어, Etgar(1977) 은 공급체인의 환경이 공급체인 리더십에 영향 을 미친다고 주장하였고, Boomer, Rubin, and 
Baldwin(2004)은 조직 냉소주의에 대해, Walumbwa and Schaubroeck(2009)는 리더의 개성에 대해 연구하였다. 하지만 공급체인 환경과 조직 냉소 주의는 공급체인 리더 입장에서 통제하기 어려 운 변수이고, 리더의 개성은 유용하지만 리더의 선발과 관련된 제한적인 함의를 가지기 때문에 또다른 선행변수에 대한 연구가 필요하다(김상 덕 2011).

둘째, 기존 공급체인 내 조직간 리더십 연구 들은 리더십과 재무성과 간 관계를 거의 다루 지 않았다. 리더십 연구가 실무적 차원에서 더 각광을 받기 위해서는 아무래도 이에 대한 명 확한 규명이 필요한데, 국내외를 불문하고 관련 연구를 거의 찾아보기 어렵다.

이에 본 연구는 공급체인 리더십의 선행변수 를 발견하고, 리더십-성과 간 관계에 영향을 미 칠 가능성이 있는 조절변수를 탐험하고자 한다. 특히, 본 연구에서 관심이 있는 공급체인 리더 십의 선행변수는 최근 Hoppner and Griffith (2011), Doyle(2010), Vandaele, Rangarajan, Gemmel, and Lievens(2007) 등의 연구에서 그 중요성이 강조되고 있는 관계적 행동(relational behavior) 변수이고, 리더십-성과 간 관계의 조 절변수로는 Brown, Trevino, and Harrison(2005) 연구에서 강조되었던 리더의 윤리성에 대해 검 정해 보고자 한다.

이를 위해 본 연구는 공급체인 리더십이 잘 나타날 수 있다고 판단되는 중소 공급업체와 대형 유통업체 간 공급체인을 대상으로 연구를 수행하였으며, 대표적인 대형 유통업체 중 하나 인 편의점 산업에 초점을 맞추었다.

요컨대 본 연구의 목적은 첫째, 공급체인 리 더의 관계적 행동들이 공급체인 리더십에 미치
는 영향을 규명하는 것이고, 둘째, 공급체인 리 더의 리더십이 공급업체의 재무성과에 미치는 영향을 규명하는 것이며, 셋째, 공급체인 리더 십과 공급업체의 재무성과 간 관계에서 리더의 윤리성이 어떠한 역할을 하는지 규명하는 것이다.

\section{II. 이론적 배경}

\section{1 공급체인 내 조직 간 리더십}

인사관리 분야의 주요 연구 개념인 리더십은 전통적으로 조직 내부의 개인 리더에 초점을 맞추었다. 그러나 $\operatorname{Bass}(1985)$ 는 변혁적 리더십 (transformational leadership)과 거래적 리더십 (transactional leadership)을 주장하면서 조직 간 관계에서 발생하는 리더십의 중요성을 강조 하였다. 실제로 조직은 조직 내의 리더와 외부 환경이 변하더라도 자체적인 구조와 규범은 쉽 게 변화되지 않기 때문에 조직특성을 유지한다 고 볼 수 있다(Morgan 1986). 때문에 조직 간 에도 리더십이 존재할 수 있다고 할 수 있다. $\mathrm{Kime}(2001)$ 은 조직 간에 발생하는 조직 간 리 더십을 "조직의 위협과 도전 그리고 기회가 되 는 조직의 내적/외적 자극들에 반응하는 능력" 으로 정의하였다.

이러한 조직 간 리더십은 조직 간 거래관계이자 독립적인 기업 간 네트워크 시스템이라 할 수 있 는 공급체인에서도 나타난다 할 수 있고(Etgar 1977, Schul, Pride, and Little 1983, Hult, Ferrell, Hurley, and Giunipero 2000), 조직 내부 구성원 간에 나타나는 리더십과 유사한 형태를 
띈다(Frazier 1983, Frazier and Sheth 1985).

Schul, Pride, and Little(1983) 과 Price(1991) 는 공급체인에서 나타나는 조직 간 리더십을 “공급체인 구성원 간 마케팅 전략과 프로그램 의 수행에 영향을 미치는 리더의 행동”이라 정 의하였다.

본 연구의 대상 산업인 편의점 산업에서도 이 러한 공급체인 내 조직간 리더십이 존재하는데, 일반적으로 공급체인 리더라 할 수 있는 편의 점 본부와 팔로워라 할 수 있는 공급업체 간에 리더십의 행사가 있을 수 있고, 그 리더십은 팔 로워의 행동에 영향을 미칠 수 있다.

하지만 앞서 언급한 바와 같이 대부분의 조직 간 리더십에 관한 연구들이 리더십과 성과변수 와의 관계에 초점을 맞추었기 때문에 공급체인 리더가 경로리더십을 과연 어떻게 가질 수 있 는가에 대해서는 밝혀진 바가 매우 적다. Etgar (1977)가 제시한 외부환경, Bommer, Rubin, and Baldwin(2004)가 제시한 조직 냉소주의, Walumbwa and Schaubroeck(2009)가 제시한 리더의 개성 등은 공급체인 리더십의 선행요인 으로 나름대로 의미가 있기는 하지만 아직 리 더십의 복잡한 메커니즘을 설명하기에는 매우 부족하고, 실무적 차원에서 적용하는데 한계를 가지고 있다.

본 연구에서는 이에 새로운 선행요인으로 관계 적 행동(Hoppner and Griffith 2011, Doyle 2010) 변수에 대해서 탐험해 보고자 한다.

\section{2 경로 리더십의 선행요인으로서 관계적 행동}

관계적 행동은 거래파트너와 협력적인 관계를
개발하기 위해 사용되는 행동이라 할 수 있다 (Hoppner and Griffith 2011, Lusch and Brown 1996). 비록 일부 학자들이 관계적 행동이 기업 의 재무적 성과를 높일 수 있다고 주장하였지 만 실제로 그러한지는 여전히 불확실한 상태 로 남아 있다(Ivens and Blois 2004, Vandaele, Rangarajan, Gemmel, and Lievens 2007). 예를 들어, Bercovitz, Jap, and Nickerson(2006), Ferguson, Paulin, and Bergeron(2005), Zhang, Cavusgil, and Roath(2003) 등의 연구는 긍정적 인 효과를 미치는 것으로 제시되고 있지만 Lusch and Brown(1996), Siguaw, Simpson, and Baker (1998)의 연구에서는 유의적인 영향을 보이지 않았다. 이는 관계적 행동과 재무적 성과 간 관 계에 제 3 의 변수가 존재하고 있음을 암시한다 고 할 수 있다.

Lusch and Brown(1996, p26)은 “자유롭게 정 보교환하고, 거래의 유연성이 확보되어 있으며, 상호 결속이 다져져 있을 때 유통경로 구성원 은 높은 수준의 성과를 달성할 수 있다"고 언 급하였데, 이는 관계적 행동과 성과 간에 긍정 적인 효과가 있을 때는 거래 파트너 간에 상 호 간 관계적 행동이 선행되어야 함을 의미한 다. 이러한 관계적 행동은 거래 파트너의 호혜 성(reciprocity)을 유도하여 거래관계를 더욱 강 화하기도 한다(Hoppner and Griffith 2011).

따라서 거래 파트너 상호 간에 더 많은 성과를 내기 위해서 더 많은 관계적 행동을 하는 것이 필요하다 할 수 있다(Fehr and Gachter 2000, Jap and Anderson 2007, Dwyer, Schurr, and Oh 1987).

이와 같은 관계적 행동은 Lipset(1975)의 관 계규범(relational norm)을 재해석한 Lusch and 
Brown(1996)에 의해 체계화되었는데, 그들은 단결(solidarity), 유연성(flexibility), 그리고 정 보교환(information exchange)으로 관계적 행 동을 설명하였다. 여기서 단결이란 관계에 큰 가치를 부여할 것이라는 상호간의 기대감을 의 미하고, 유연성은 상황이 바뀌었을 때 거래파트 너의 요청에 의해 기존에 체결한 약속을 기꺼 이 조정할 것이라는 기대감을 의미하며, 정보교 환은 유통경로 구성원들이 유용한 정보를 자유 롭고 활발하게 교환할 것이라는 기대감을 말한다.

또한 관계적 행동은 Gronroos(1982) 이후 많 은 Rafiq and Ahmed(2000)에 의해 체계화 된 내부마케팅을 조직 간 관계에서 적용할 수 도 있다. 비록 내부마케팅이 조직 내의 리더와 종 업원 간 관계를 설명하는데 주요한 도구이지만 마치 하나의 기업처럼 움직이고 있는 조직 간 네트워크 관계에서는 조직 간 관계가 조직 내의 구성원 간 관계와 유사하기 때문이다(Frazier and Sheth 1985).

이러한 내부마케팅의 구성요소는 매우 다양하 게 연구되어 왔다. 예를 들어, 훈련, 경영지원 의사소통, 보상, 종업원 참여(Gronroos 1982), 종 업원개발, 보상, 기업비전의 공유(Foreman and Money 1995), 종업원 참여, 피드백, 훈련, 정보전 달, 의사소통, 교육(Ballantyne 2000), 서비스표준 제시, 교육훈련, 보상(Keleman and Papasolomou 2007) 등이 그 구성요소라 할 수 있다. 하지만 아직 통일된 정의는 없다고 할 수 있고, 연구마 다 연구대상산업에 맞게 내부마케팅의 구성요 소를 차별적으로 적용하고 있다.

본 연구에서는 기존 연구들에서 사용된 관계 규범과 내부마케팅의 구성요소들을 토대로 본 연구의 대상산업인 편의점 공급체인의 공급업
체 납품담당자들을 대상으로 사전 조사를 실시 하였고, 조사 결과를 토대로 교육훈련, 공정한 보상, 조직간 의사소통, 비전제시를 편의점 공 급체인에서 가장 중요한 관계적 행동 요소로 선정하였다.

\section{3 공급체인 리더십의 결과요인으로서 재무성과}

공급체인에서 성과는 공급체인의 목표달성 정 도 또는 효율성, 효과성, 공정성 등의 복합적인 개념으로 정의될 수 있고, 재무적인 성과와 행동 적인 성과가 모두 고려되어야 한다(Coughlan, Anderson, Stern, and El-Ansary 2006). 공급 체인 내 조직간 리더십의 성과도 이와 같은 맥 락이라 할 수 있다. 하지만 기존의 조직 간 리 더십의 성과관련 변수들은 거의 모두 팔로워 조직의 행동적인 성과에 초점을 맞추고 있다. 앞서 언급한 바와 같이 갈등의 감소, 파트너 동 기부여, 조직 결속, $\mathrm{CRM}$ 이행, 만족, 추가적인 역할, 영역초월행동, 조직동일시, 조직시민행동, 재계약의도(Schul, Pride, and Little 1983, Price 1993, Mehta 2000, Hult, Ferrell, Hurley, and Giunipero 2000, Yueh, Lee, and Barnes 2010, Toor and Ofori, 2009, 정대용, 이세호 2008, 장 석인 2009, 김상덕 2011) 등의 변수는 모두 행 동적인 성과라 할 수 있다.

하지만 현실적으로 공급체인의 가장 중요한 성과인 재무적 성과와 리더십과의 관계를 규명 한 연구는 조직 간 리더십 연구에서 찾아보기 힘들다.

본 연구는 이러한 리더십-성과 간 기존 연구 들이 규명하지 못하였던 리더십-재무성과 간 
관계를 규명하고자 한다. 재무적 성과에는 매출 과 시장점유율(Heweett and Bearden 2001), 매출신장률, 매출기여도, 이익기여도, 성장기여 도(Hibbard, Kumar, and Stern 2001), 수익성 (Pelham and Wilson 1996, Jap 1999) 등이 있다. 이러한 재무성과는 구성원 간 결속이 강한 공 급체인에서 더 높게 나타나기 때문에(Morgan and Hunt 1994), 공급체인 내 리더의 리더십과 밀접한 관계가 있을 것으로 생각할 수 있다.

\section{4 공급체인 리더십-재무성과 간 조절변수로서 리더의 윤리성}

리더의 윤리성은 오랜 기간 많은 학자들에 의 해 그 중요성이 언급되어 왔지만 실제로 본격 적인 학술적 연구가 이루어진 것은 역사가 짧 다. 최근 리더십 연구에서 그 중요성이 부각되 고 있는 윤리적 리더십(Ciulla 1998, Zhu, May and Avolio 2004, Brown and Trevino 2006)은 이러한 리더의 윤리성에 착안한 것이라 할 수 있다.

Trevino, Hartman, and Brown(2000)은 리더 가 가지는 윤리성을 도덕적 인간(moral person) 과 도덕적 관리자(moral manager)의 두가지 차원으로 구분하였는데, 도덕적 인간은 윤리적 리더의 인간으로서 질을 의미하고, 도덕적 관리 자는 리더의 지위를 도구로 활용하여 팔로워들 의 윤리적 행동을 촉진하는 것을 의미한다. 따 라서 리더의 윤리성은 강한 도덕적 인간이면서 동시에 강한 도덕적 관리자일 때 발생한다고 할 수 있다. 약한 도덕적 인간이면서 강한 도 덕적 관리자는 팔로워들에게 위선자로 보여질 수 있고, 반대로 약한 도덕적 관리자이면서 강
한 도덕적 인간은 윤리에 대해 관심이 없는 사 람으로 인식될 수 있다(Trevino, Brown, and Hartman 2003).

요컨대 리더의 윤리성은 "개인적인 행동과 개 인간 관계를 통해 규범적으로 적절한 행동을 보여주는 것, 그리고 양방향 커뮤니케이션, 강화, 의사결정 등을 통해 팔로워들에게 그러한 행동 을 장려하는 것(Brown, Trevino, and Harrison $2005, \mathrm{p} 120) "$ 이라 할 수 있다.

이러한 리더의 윤리성은 직무만족, 조직결속, 문제에 대한 보고의도, 직무외 추가적 역할행동 의도, 건설적인 제안, 조직시민행동, 일탈행동 감 소(Brown, Trevino and Harrison 2005, Neubert, Carlson, Kacmar, Roberts, and Chonko 2009, Toor and Ofori 2009, Walumbwa and Schaubroeck 2009, Mayer, Kuenzi, Greenbaum, Bardes, and Salvador 2009) 등 유통경로의 행동적인 성과 변수이면서, 재무적인 성과변수와 상관관계가 높은 변수들과 밀접한 관련성이 있다.

\section{III. 가설수립 및 연구모형 설정}

\section{1 관계적 행동과 공급체인 리더십}

앞서 언급한 바와 같이 본 연구에서는 교육훈 련, 공정한 보상, 조직 간 의사소통, 비전제시를 편의점 공급체인에서 가장 중요한 관계적 행동 요소로 선정하였다. 각각의 구성요소가 공급체 인 리더의 공급체인 리더십에 어떠한 영향을 미치는 지 가설을 수립해보면 다음과 같다.

먼저 교육훈련은 편의점 본부(공급체인 리더) 
의 공급체인 리더십을 강화시킬 가능성이 높다. 교육훈련은 공급업체(공급체인 팔로워)의 역량 을 강화하여 더 나은 성과를 창출하기 위한 목적 을 가지고 있다(Ooncharoen and Ussahawanitchakit (2009). 특히 상품 개발 능력이 부족하거나 고 객의 욕구를 파악하기 어려운 공급업체는 경쟁 력 있는 상품을 효율적으로 공급하기 어렵다. 때문에 대형 유통업체인 편의점 본부의 교육 훈련은 공급업체의 역량을 강화시키며 이는 공 급업체의 거래관계에 대한 만족을 강화시킨다 (Tax and Brown 1998).

이 때 중소 공급업체는 편의점 본부의 이러한 교육훈련에 대해 지적 자극을 받고 개별적인 배려를 받는다고 여길 가능성이 높다. 또한 성 과에 대한 보상차원에서 이루어지는 교육훈련 은 상황적 보상으로 받아들여 질 수 있다. 전자 는 Bass and Avolio(1990)가 주장한 변혁적 리 더십을, 후자는 $\operatorname{Bass}(1985)$ 가 주장한 거래적 리 더십을 느끼게 하는 중요한 계기가 된다. 뿐만 아니라 교육훈련은 편의점 본부가 공급업체에 결속하고 있다는 신호로 작용하기 때문에 본 부에 대한 참여적 리더십 또는 지원적 리더십 (Barnettt and Arnold 1989, Mehta 2000)을 지 각하게 할 가능성이 높다. 따라서 다음과 같은 가설을 수립할 수 있다.

가설 1 : 대형 유통업체와 중소 공급업체 간 공급체인에서 유통업체의 교육훈련은 공급체인 리더십을 강화할 것이다.

다음으로 공정한 보상도 유통업체의 공급체인 리더십을 강화시킬 가능성이 높다. Berry(1999) 는 서비스 종업원들이 더 많은 것을 얻을수록
조직의 부분 소유자(part-owner)로서의 감정을 갖게 되고, 이러한 감정이 조직의 성공을 유지 하기 위해 기꺼이 일하게 한다는 사실을 발견 하였다. 마찬가지로 공급업체들은 그들이 일한 만큼, 또는 그 이상의 보상을 받았을 때, 공급 체인 전체의 목표를 위해 더욱 노력하고, 리더 의 방침에 더 잘 따르게 될 것이다. 특히, 성과 에 대한 보상은 중소 공급업체 입장에서는 매 우 큰 관심이기 때문에 이러한 효과가 더 잘 나타난다고 할 수 있다(Forrester 2000).

여기서 성과에 대한 공정한 보상은 무엇보다 도 유통업체의 거래적 리더십으로 인식될 수 있다. 공정한 보상 자체가 인센티브로 작용하 고, 더 높은 성과를 달성하게 하는 동기부여가 되기 때문이다(Bass 1985, Klimoski and Hayes 1980, Kelemen and Papasolomou 2007). 뿐만 아니라 높은 성과를 달성한 공급업체에게는 다 른 공급업체와는 다른 개별적인 배려로 받아들 여질 수 있고, 성과가 낮은 공급업체에게는 분 발을 고취하는 의미로 작용할 수 있다(Bass and Avolio 1990). 따라서 다음과 같은 가설을 수립 할 수 있다.

가설 2: 대형 유통업체와 중소 공급업체 간 공급체인에서 유통업체의 공정한 보 상은 공급체인 리더십을 강화할 것 이다.

관계적 행동의 세 번째 구성요소인 조직 간 의사소통 또한 유통업체의 공급체인 리더십을 강화할 가능성이 높다. 의사소통은 공급체인 구 성원 간 거래관계를 유지시켜주는 접착제와 같 은 역할을 하고 있기 때문에 원활한 의사소통 
이 이루어지지 않으면 공급체인 구성원 간 관 계는 강한 결속이 나타나기 어렵다(Mohr and Nevin 1990). 이러한 의사소통은 비대칭적 의 존구조를 가지고 있는 거래 파트너간 관계에서 마저도 결속을 강화하는데(김상덕, 정연승 2008), 일반적으로 비대칭적 의존구조를 가지고 있는 대형 유통업체와 중소 공급업체 간 관계에서도 매우 중요한 역할을 한다.

특히, 의사소통은 공급체인에서 구성원 간 조 직 동일시를 유도하고(Ullrich, Wieseke, Christ, Schulze, and Dick 2007), 팔로워의 냉소주의를 줄여주어 리더의 변혁적 리더십을 강화시킨다 (Boomer, Rubin, and Baldwin 2004). 이는 유 통업체의 의사소통이 공급업체들의 신념, 욕구, 가치관을 바꾸어 혁신적인 변화를 유도하기 때 문이라 할 수 있다(Bass and Avolio 1990). 따 라서 다음과 같은 가설을 수립할 수 있다.

가설 3: 대형 유통업체와 중소 공급업체 간 공급체인에서 유통업체의 조직 간 의사소통은 공급체인 리더십을 강화 할 것이다.

마지막으로 비전제시 또한 관계적 행동의 주 요한 요소로서 유통업체의 리더십 형성에 영향 을 미칠 가능성이 높다. 앞서 언급한 것처럼 비 전 제시는 관계적 행동의 주요 구성요소이면서 (Foreman and Money 1995, Hult 1997) 동시 에 변혁적 리더십의 핵심적 요소라 할 수 있다. 특히, 조직 구성원에게 비전과 미션을 제시하면 서 리더에 대한 존경, 신뢰를 갖게 하고, 구성 원의 각성과 분발을 유도하는 카리스마적 리더 십은 비전제시와 밀접한 연관이 있다(Mehta
2000). 이러한 비전 제시는 공급업체가 유통업 체에 서비스를 제공하는 과정에서 핵심적인 역 할을 하기도 한다(Congram and Friedman 1991).

유통업체가 공급업체에 대해 감정적인 자극을 통한 즉각적 행동변화 보다 믿음과 가치, 문제 인식과 해결에 있어서 공급업체를 변화시키고 자 한다면 공급업체는 자연스럽게 유통업체의 변혁적 리더십을 느끼게 될 것이고(Bass 1990), 공급업체의 상황에 맞는 비전 제시는 개별적인 배려로 인식될 수도 있다(Bass and Avolio 1997). 따라서 다음과 같은 가설을 수립할 수 있다.

가설 4: 대형 유통업체와 중소 공급업체 간 공 급체인에서 유통업체의 비전제시는 공급체인 리더십을 강화할 것이다.

\section{2 공급체인 리더십과 재무성과}

앞서 언급한 것처럼 공급체인 리더십과 재무 성과 간 관계에 대해서는 밝혀진 바가 매우 적 다. 하지만 유통경로의 재무성과는 구성원 간 결속이 강한 상태에서 더 높게 나타나기 때문 에(Morgan and Hunt 1994), 공급체인 리더십 과 밀접한 관계가 있을 가능성이 높다. 더욱이 규범적인 측면에서 보았을 때, 공급체인 리더십 의 궁극적인 목표는 재무성과와 어떠한 형태로 든 관련이 있어야 한다. 공급체인 리더십도 조 직의 목표를 달성하기 위한 수단이기 때문이다.

지금까지 실시된 공급체인 리더십의 결과변수 에 관한 연구들에는 재무성과와 직접 관련된 것들을 찾아보기는 힘들지만 공급체인 리더십 이 재무성과를 강화할 가능성이 있다는 것을 추측하게 한다. 예를 들어, Dukerich, Golden, 
and Shortell(2002)에서 주장한 협력적 행동, Carmeli, Gilat, and Waldman (2007)에서 주장 한 직무만족 등은 리더십이 궁극적으로 재무성 과를 강화할 수 있음을 보여주는 증거라 할 수 있다.

편의점 공급체인의 경우 편의점 본부와 공급 업체가 상호계약에 의해 하나의 시스템처럼 운 영되긴 하지만 제품 및 서비스의 품질 관리, 공 급체인 전략의 이행, 공급업체 기회주의의 통제 측면에서 어려움을 겪고 있다(Coughlan, Anderson, Stern, and El-Ansary 2006). 이러한 문제는 공 급업체의 재무성과에 부정적인 영향을 미친다.

하지만 유통업체의 공급체인 리더십은 이러한 문제들을 극복하게 하여 재무성과를 강화할 수 있다(김상덕 2011). 따라서 다음과 같은 가설을 수립할 수 있다.

가설 5: 대형 유통업체와 중소 공급업체 간 공급체인에서 유통업체의 리더십은 공 급업체의 재무성과를 강화할 것이다.

\section{3 공급체인 리더십-재무성과 간 관계에서 리더 윤리성의 역할}

앞서 언급한 바와 같이 리더의 윤리성은 개인 적인 행동과 개인간 관계를 통해 규범적으로 적절한 행동을 보여주는 것, 그리고 양방향 커뮤 니케이션, 강화, 의사결정 등을 통해 팔로워들에 게 그러한 행동을 장려하는 것(Brown, Trevino, and Harrison 2005, p120)이라 할 수 있다.

이러한 윤리성은 리더의 리더십과 팔로워의 성과 간 관계에 영향을 준다. 이는 사회교환이 론의 호혜성(reciprocity) 원칙(Blau 1964)에 근
거한다. 구체적으로 말하면 팔로워들은 리더가 자신에게 선하고 공정하게 대했다고 믿을 때, 시민행동과 같은 리더에게 이로운 행동을 되 돌려 줄 의무감을 가진다. 반면, 비윤리적인 리 더에게는 일탈행동, 파괴적 행동 등을 보인다 (Brown and Mitchell 2010).

따라서 윤리적인 유통업체의 공급체인 리더십 은 공급업체의 윤리적 행동, 조직시민행동 등을 유도하여 기대했던 것보다 더 큰 성과를 초래 할 가능성이 높고, 비윤리적인 유통업체의 공급 체인 리더십은 공급업체의 일탈행동, 기회주의 적 행동 등을 유도하여 기대했던 것보다 더 낮 은 성과를 초래할 가능성이 높다. 따라서 다음 과 같은 가설을 수립할 수 있다.

가설 6: 대형 유통업체의 공급체인 리더십이 중소 제조업체의 재무성과에 미치는 긍정적인 영향은, 유통업체가 비윤리 적인 경우보다 윤리적인 경우에 더 클 것이다.

이상의 내용을 종합하여 도식화하면 다음 〈그 림 1) 연구모형과 같다.

\section{IV. 연구방법}

\section{1 표본 및 자료수집}

본 연구는 편의점 공급체인에서 대형 유통업 체인 편의점 본부와 중소 공급업체 간 관계를 중심으로 연구를 진행하였다. 이를 위해 본 연 
〈그림 1〉

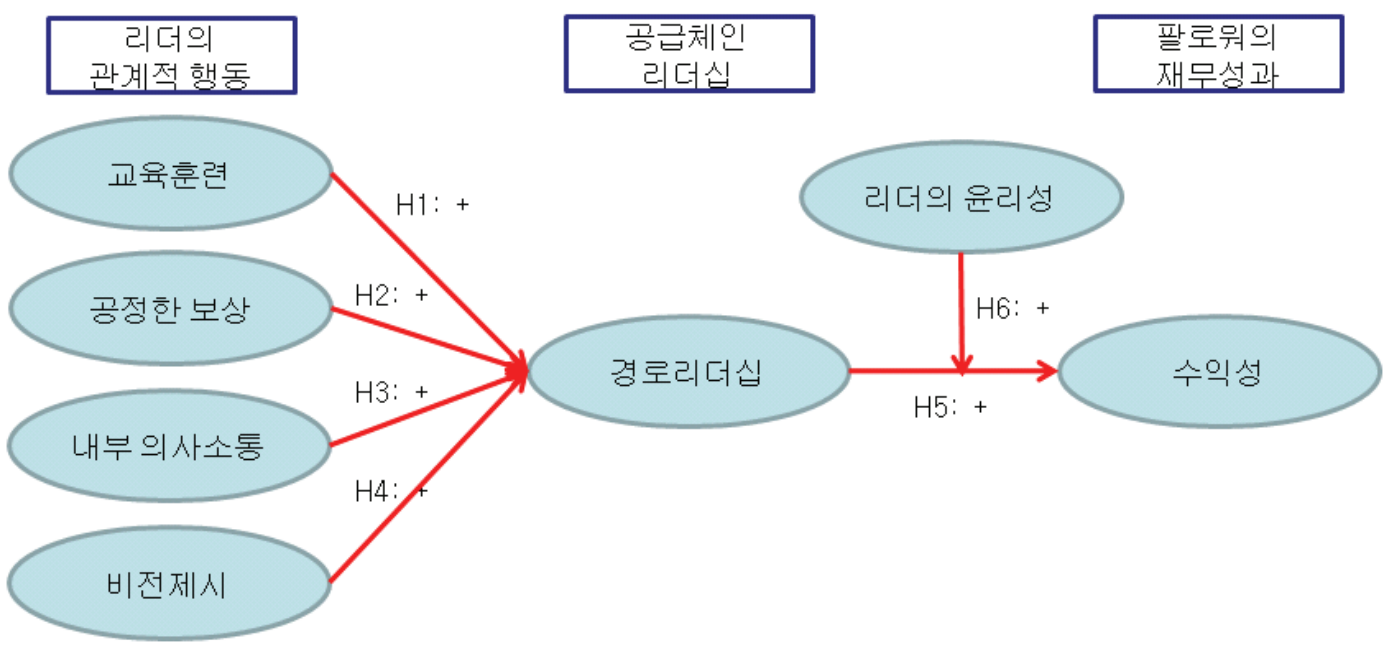

구는 국내 편의점 산업의 대표적인 업체인 훼 미리마트, GS25, 7-Eleven, 바이더웨이, 미니스 톱 등 5 개 업체에 상품을 공급하는 공급업체 217 개사를 대상으로 설문조사를 실시하였다. 설 문조사는 공급업체의 납품담당자를 대상으로 하 였으며, 전문조사기관의 면접원이 방문하여 $1: 1$ 대인면접 방식으로 실시하였다. 표본은 편의점 업체의 협조 하에 공급업체 리스트에서 무작위 로 선정되었다. 표본 수는 5 개 업체의 공급업체 들이 골고루 포함되도록 구성하였으며, 전문면 접원에 의해 조사되었기 때문에 217 부의 설문 지 모두가 유효한 설문지였다.

사실 관계적 행동, 리더십, 공급체인 재무성과 등은 거래파트너 상호 간에 이루어지는 것이므 로 양방향으로 측정하는 것이 바람직하다. 하지 만 본 연구의 대상 산업인 편의점 공급체인에 서는 공급업체의 수에 비해 편의점 본부의 수 가 매우 적기 때문에 거래 파트너 간에 $1: 1$ 로 측정한다는 것은 현실적으로 매우 어렵다. 때문 에 본 연구에서는 공급업체들에 대해서만 설문
조사를 실시하였음을 밝혀 둔다.

\section{2 변수의 조작적 정의}

본 연구에서 언급된 변수들은 관련 분야 연구 에서 신뢰성과 타당성이 검증된 측정도구를 사 용하였다.

먼저 공급체인 리더십은 Hult, Ferrell, Hurley, Giunipero(2000)의 측정도구를 편의점 공급체인 에 맞게 수정하여 각각 10 항목으로 측정하였다. 다음으로 관계적 행동의 구성요소인 교육훈련, 공정한 보상, 조직 간 의사소통, 비전제시는 Kellemen, Papasolomou(2007), Shiu and Yu (2011) 연구를 활용해 각각 3 항목, 4 항목, 7항 목, 3항목으로 측정하였다.

다음으로 재무성과는 Pelham and Wilson(1996) 연구를 활용해 5 항목으로 측정하였고, 윤리성은 Brown and Trevino(2006) 연구를 활용해 10항 목으로 측정하였다.

모든 측정항목은 리커트 5점 척도(1점: 전혀 
그렇지 않다. 5점: 매우 그렇다)를 이용하였다. 모든 측정항목들은 부록에 제시되었다.

\section{$\mathrm{V}$. 실증분석}

\section{1 조사대상의 통계적 특성}

조사대상 공급업체의 통계적인 특성은 〈표 1〉 과 같다. 주 거래 편의점은 훼미리마트(21.2\%),
GS25(21.2\%), 7-Eleven(19.8\%), 바이더웨이 (19.4\%), 미니스톱(16.6\%)이 고루 분포되어 있 고, 납품 상품군은 식품(63.6\%)이 가장 많았으 며, 종업원 수는 30명 미만(26.7\%)과 100-999 명(26.7\%)이 가장 많았다.

공급업체의 연매출은 100 억원 미만(37.3\%)이 가장 많았고, 거래기간은 5년 미만(34.1\%)이 가 장 많았다. 전반적으로 보았을 때, 표본의 특성 이 어느 한쪽으로 편중되지 않고, 우리나라 편 의점 공급업체를 잘 설명해 줄 수 있다고 판단 되었다.

〈Table 1〉 Respondents Characteristics $(n=217)$

\begin{tabular}{|c|c|c|c|c|}
\hline \multicolumn{2}{|c|}{ Characteristics } & Frequency & $\%$ & Sum \\
\hline \multirow{6}{*}{$\begin{array}{l}\text { Convenience store } \\
\text { dealing with }\end{array}$} & Family Mart & 46 & 21.2 & \multirow{6}{*}{$217(100.0)$} \\
\hline & GS25 & 46 & 21.2 & \\
\hline & 7-Eleven & 43 & 19.8 & \\
\hline & By the Way & 42 & 19.4 & \\
\hline & Mini Stop & 36 & 16.6 & \\
\hline & ect. & 4 & 1.8 & \\
\hline \multirow{3}{*}{ Product category } & food & 138 & 63.6 & \multirow{3}{*}{$217(100.0)$} \\
\hline & apparel/culture & 16 & 7.4 & \\
\hline & general consumer goods & 63 & 29.0 & \\
\hline \multirow{5}{*}{ Number of employees } & under 30 & 58 & 26.7 & \multirow{5}{*}{$217(100.0)$} \\
\hline & $30-99$ & 47 & 21.7 & \\
\hline & 100-999 & 58 & 26.7 & \\
\hline & over 1,000 & 34 & 15.7 & \\
\hline & non-response & 20 & 9.2 & \\
\hline \multirow{4}{*}{$\begin{array}{l}\text { Annual sales } \\
\text { (100 million Won) }\end{array}$} & under 100 & 81 & 37.3 & \multirow{4}{*}{$217(100.0)$} \\
\hline & 100-999 & 62 & 29.0 & \\
\hline & over 1,000 & 50 & 23.0 & \\
\hline & non-response & 23 & 10.6 & \\
\hline \multirow{4}{*}{$\begin{array}{l}\text { Relationship } \\
\text { length(Year) }\end{array}$} & under 5 & 74 & 34.1 & \multirow{4}{*}{$217(100.0)$} \\
\hline & $5-9$ & 51 & 23.5 & \\
\hline & over 10 & 62 & 28.6 & \\
\hline & non-response & 30 & 13.8 & \\
\hline
\end{tabular}




\section{2 구성개념의 신뢰성 및 타당성 검토}

본 연구에서는 Cronbach's alpha 값을 활용하 여 신뢰성을 검토하였고, 평균분산추출값(average variance extracted; AVE), 합성신뢰도(composite reliability; $\mathrm{CR}$ ), 변수간 상관계수를 이용하여 수렴타당성과 판별타당성을 검토하였다. 구성개 념의 신뢰성과 수렴타당성 검토 결과〈표 2〉에

〈Table 2〉 Reliability, Average Variance Extracted, and Composite Reliability

\begin{tabular}{|c|c|c|c|c|c|c|}
\hline Variable & $\begin{array}{l}\text { Number of Items } \\
\text { (Items deleted) }\end{array}$ & $\begin{array}{c}\text { Factor } \\
\text { Loadings }\end{array}$ & t-value & $\mathrm{CR}$ & AVE & $a$ \\
\hline \multirow{3}{*}{ Training } & \multirow{3}{*}{3} & 0.917 & 69.23 & \multirow{3}{*}{0.913} & \multirow{3}{*}{0.779} & \multirow{3}{*}{0.857} \\
\hline & & 0.910 & 52.43 & & & \\
\hline & & 0.816 & 22.55 & & & \\
\hline \multirow{4}{*}{ Fair reward } & \multirow{4}{*}{4} & 0.938 & 112.69 & \multirow{4}{*}{0.965} & \multirow{4}{*}{0.875} & \multirow{4}{*}{0.952} \\
\hline & & 0.931 & 85.55 & & & \\
\hline & & 0.940 & 80.73 & & & \\
\hline & & 0.932 & 87.68 & & & \\
\hline \multirow{3}{*}{ Offering visions } & \multirow{3}{*}{3} & 0.893 & 35.21 & \multirow{3}{*}{0.911} & \multirow{3}{*}{0.775} & \multirow{3}{*}{0.851} \\
\hline & & 0.944 & 103.95 & & & \\
\hline & & 0.797 & 13.27 & & & \\
\hline \multirow{6}{*}{$\begin{array}{c}\text { Inter- }^{-} \\
\text {organizational } \\
\text { communication }\end{array}$} & \multirow{6}{*}{$6(1)$} & 0.808 & 30.99 & \multirow{6}{*}{0.902} & \multirow{6}{*}{0.610} & \multirow{6}{*}{0.869} \\
\hline & & 0.609 & 9.08 & & & \\
\hline & & 0.834 & 19.42 & & & \\
\hline & & 0.857 & 44.95 & & & \\
\hline & & 0.716 & 16.41 & & & \\
\hline & & 0.834 & 43.42 & & & \\
\hline \multirow{9}{*}{$\begin{array}{l}\text { Supply chain } \\
\text { leadership }\end{array}$} & \multirow{9}{*}{$9(1)$} & 0.811 & 25.37 & \multirow{9}{*}{0.944} & \multirow{9}{*}{0.656} & \multirow{9}{*}{0.933} \\
\hline & & 0.790 & 21.52 & & & \\
\hline & & 0.754 & 18.42 & & & \\
\hline & & 0.792 & 22.75 & & & \\
\hline & & 0.798 & 27.72 & & & \\
\hline & & 0.831 & 36.30 & & & \\
\hline & & 0.823 & 29.84 & & & \\
\hline & & 0.816 & 26.40 & & & \\
\hline & & 0.868 & 30.10 & & & \\
\hline \multirow{4}{*}{$\begin{array}{c}\text { Financial } \\
\text { performance }\end{array}$} & \multirow{4}{*}{$4(1)$} & 0.923 & 68.48 & \multirow{4}{*}{0.961} & \multirow{4}{*}{0.860} & \multirow{4}{*}{0.943} \\
\hline & & 0.931 & 80.74 & & & \\
\hline & & 0.932 & 96.81 & & & \\
\hline & & 0.922 & 59.47 & & & \\
\hline
\end{tabular}


나타난 바와 같이 모든 수치들이 권고치를 초 과하고 있어 측정도구가 신뢰성과 수렴타당성 을 가지고 있는 것으로 판단하였다.

변수의 신뢰성과 타당성 확보를 위한 정제과 정은 각각의 개념별로 측정도구가 Cronbach's alpha값의 일반적인 기준(Nunnally and Bernstein 1994)인 0.7을 상회하는 지, 확인적 요인분석 후 측정 항목들과 해당 구성개념들을 연결하는 표 준 요인적재량들이 통계적으로 $95 \%$ 신뢰구간에 서 유의적인지( $t>1.96)$ (Anderson and Gerbing, 1988), 확인적 요인분석으로부터 얻어진 표준 요인 부하량을 이용하여 합성신뢰도(composite reliability)와 평균분산추출값(average variance extracted; AVE)을 계산하였을 때, 합성신뢰 도가 .70을 상회하고, 평균분산추출값이 .50을 상회하는지(Bagozzi and Yi, 1988) 검토하는 과 정을 통해 이루어졌다. 이 과정에서 조직 간 의 사소통의 1 개 항목과 공급체인 리더십의 1 개 항목은 변수의 신뢰성과 타당성을 저해하고 있 었기 때문에 제거되었다.

한편, 판별타당성은 한편, 판별타당성은 모든 구성개념 간 상관계수의 값이 평균분산추출값 의 제곱근 보다 작은지 여부로 판단하였는데,
〈표 3〉에 나타난 바와 같이 모든 상관계수가 평균분산추출값의 제곱근 보다 작게 나타나서 판별타당성이 있는 것으로 판단하였다.

\section{3 가설 검정}

\subsection{1 주효과에 대한 가설 검정}

주효과에 대한 가설 검정을 위해 본 연구에서 는 PLS분석을 이용하였다. 본 연구에서 Lisrel 이나 AMOS 등을 이용한 구조방정식 모형분석 을 실시하지 않은 이유는 세가지가 있다. 첫째, 본 연구의 변수 간 관계에 대한 탐험적 성격의 목적에 Lisrel보다 PLS가 더 적합하다. Lisrel은 전체 연구모형의 적합도만 제시하기 때문에 “관계적 행동과 리더십”, "리더십과 성과”간 관 계를 구분해서 적합도를 제시하는 PLS에 비해 개별 변수들 간 인과관계를 규명하고자 하는 본 연구의 목적을 덜 충족시킨다고 할 수 있다. 둘째, Lisrel은 측정변수들이 다변량 정규분포 를 따른다고 가정하고 충분한 표본 수를 확보 해야 하지만 PLS는 모수들의 분포를 가정하지 않으므로 본 연구처럼 표본 수가 부족한 경우

〈Table 3〉 Correlation and Discriminant Validity Test

\begin{tabular}{|c|c|c|c|c|c|c|}
\hline & 1 & 2 & 3 & 4 & 5 & 6 \\
\hline 1 & $0.882^{*}$ & & & & & \\
\hline 2 & 0.705 & $0.935^{*}$ & & & & \\
\hline 3 & 0.800 & 0.753 & $0.880^{*}$ & & & \\
\hline 4 & 0.686 & 0.564 & 0.628 & $0.781^{*}$ & & \\
\hline 5 & 0.777 & 0.684 & 0.748 & 0.697 & $0.810^{*}$ & \\
\hline 6 & 0.637 & 0.540 & 0.705 & 0.566 & 0.682 & $0.927^{*}$ \\
\hline
\end{tabular}

1. Training, 2. Fair reward, 3. Offering visions, 4. Inter-organizational communication,

5. Supply chain leadership, 6. Financial performance.

* square root of average variance extracted. 
더 적절하다고 할 수 있습니다. 특히, 리더 윤 리성의 조절효과를 검정하기 위해 표본을 두 개로 나누었을 때는 표본 수가 너무 적어서 Lisrel분석 결과를 신뢰하기 어렵다.

셋째, 리더 윤리성의 조절효과를 검정하기 위 해 표본을 나누고 분석해 보았을 때, 요인 불확 정성(factor indeterminacy) 문제가 발생하였으 나 PLS에서는 안정적인 추정치를 제공하였다.

따라서 본 연구에서는 분포에 대한 가정이 없 고, 표본 수에 덜 민감한(Chin 2004) PLS분석을 사용하였고, 경로의 유의성을 검정하기 위해 부 츠트랩 재표본(bootstrap re-sampling) 절차를 이 용하였다. 분석결과는 다음 〈표 4>에 제시하였다.

분석결과 모형의 설명력이 Falk and Miller(1992) 가 제시한 $10 \%$ 이상의 설명력을 보여(72.0\%, 48.5\%), 모형 적합도에 문제가 없다고 판단되었다.

다음으로 주효과에 대한 가설검정 결과를 살 펴보면 다음과 같다. 먼저 대형 유통업체의 교 육훈련이 공급체인 리더십을 강화할 것이라는 가 설 1을 보면, 교육훈련이 공급체인 리더십에 유의 적인 正의 영향을 미쳤다(계수 $=.347, \mathrm{t}=4.400$ ).
따라서 가설 1 은 채택되었다.

둘째, 대형 유통업체의 공정한 보상이 공급체 인 리더십을 강화할 것이라는 가설 2 를 보면, 공정한 보상이 공급체인 리더십에 유의적인 正 의 영향을 미쳤다(계수 $=.246, \mathrm{t}=.3 .035$ ). 따라 서 가설 2는 채택되었다.

셋째, 대형 유통업체의 조직 간 의사소통이 공 급체인 리더십을 강화할 것이라는 가설 3 을 보 면, 조직 간 의사소통은 공급체인 리더십에 유 의적인 正의 영향을 미쳤다(계수=.281, $t=.3 .240)$. 따라서 가설 3 은 채택되었다.

넷째, 대형 유통업체의 비전 제시가 공급체인 리더십을 강화할 것이라는 가설 4 를 보면, 비전 제시는 공급체인 리더십에 유의적인 영향을 미 치지 않았다(계수 $=.062, \mathrm{t}=1.207$ ). 따라서 가설 4 는 기각되었다.

마지막으로 공급체인 리더십이 공급업체의 재 무성과를 강화할 것이라는 가설 5 를 보면, 공급 체인 리더십은 재무성과에 유의적인 正의 영향 을 미쳤다(계수 $=.697, \mathrm{t}=17.368)$. 따라서 가설 5 는 채택되었다.

〈Table 4〉 Results of Partial Least Square Estimations

\begin{tabular}{|c|c|c|c|c|c|}
\hline Hypothesis & Path & Coefficient & $\begin{array}{l}\text { Standard } \\
\text { error }\end{array}$ & $\mathrm{t}$-value & Result \\
\hline H1 & $\begin{array}{c}\text { Training } \rightarrow \\
\text { Supply chain leadership }\end{array}$ & 0.347 & 0.078 & $4.400^{*}$ & supportec \\
\hline $\mathrm{H} 2$ & $\begin{array}{c}\text { Fair reward } \rightarrow \\
\text { Supply chain leadership }\end{array}$ & 0.246 & 0.081 & $3.035^{*}$ & supportec \\
\hline H3 & $\begin{array}{c}\text { Inter-organizational communication } \rightarrow \\
\text { Supply chain leadership }\end{array}$ & 0.281 & 0.086 & $3.240^{*}$ & supportec \\
\hline $\mathrm{H} 4$ & $\begin{array}{c}\text { Offering visions } \rightarrow \\
\text { Supply chain leadership }\end{array}$ & 0.076 & 0.062 & 1.207 & $\begin{array}{c}\text { not } \\
\text { supportec }\end{array}$ \\
\hline $\mathrm{H} 5$ & $\begin{array}{l}\text { Supply chain leadership } \rightarrow \\
\text { Financial performance }\end{array}$ & 0.697 & 0.040 & $17.368^{*}$ & supportec \\
\hline
\end{tabular}

* $\left.\left.\mathrm{p}<.01, \mathrm{R}_{(\mathrm{H} 1-\mathrm{H} 4}^{2}\right) .720, \mathrm{R}^{2}{ }_{(\mathrm{H} 5}\right) .485$ 


\subsection{2 리더 윤리성의 조절효과에 대한 가설검정}

본 연구는 대형 유통업체의 관계적 행동이 공 급체인 리더십에 미치는 영향에 대한 관심 뿐 아니라 리더 윤리성이 공급체인 리더십과 공급 업체의 재무성과 간 관계에 어떠한 역할을 하 는지에도 관심이 있다. 이를 위해 본 연구는 대 형 유통업체의 리더 윤리성이 어떠한 조절효과 를 가지는 지 검정하였다.

먼저 편의점 업체들의 윤리성을 공급업체들에 게 5점 척도로 평가하게 하고, 측정된 윤리성 점수의 중앙치(median)를 구하였다. 구해진 중 앙치는 3.67점으로 나타났는데, 본 연구에서는 리더 윤리성이 중앙치보다 큰 집단을 고윤리 집단 $(n=108)$ 으로, 중앙치 보다 작은 집단을 저 윤리 집단 $(n=104)$ 로 구분하였다. 이 때, 중앙 치를 보인 5 개 표본은 분석에서 제외하였다.

이렇게 하여 구분된 두 개의 표본을 가지고 동일한 PLS 구조분석을 실시하였다. 이 때, 경 로계수의 집단간 차이는 $\mathrm{Chin}$ (2000)이 제시한 통계량 ${ }^{1)}$ 을 활용하여 검정하였다. 조절효과 분
석 결과는 다음 〈표 5〉와 같다.

리더 윤리성이 높은 집단일 경우 공급체인 리 더십이 재무성과에 미치는 영향이 더 강할 것 이라는 가설 6 을 검정해 보면 다음과 같다. 먼 저 고윤리 집단과 저윤리 집단 모두에서 공급 체인 리더십은 재무성과에 유의적인 正의 영향 을 미쳤다(각각 계수 $=.644, \mathrm{t}=10.953$; 계수 $=.447, \mathrm{t}=6.132)$. 또한 집단간 차이를 보여주는 Chin의 t통계량이 $\mathrm{p}<.05$ 수준에서 유의적으로 나타났다 $(\mathrm{t}=2.121)$. 뿐만 아니라 고윤리 집단 의 계수와 t값이 저윤리 집단 보다 높게 나타 났다. 따라서 가설 6 은 채택되었다.

\section{VI. 결 론}

\section{1 연구결과의 요약 및 기각된 가설에 대한 추론}

이상의 가설검정 결과, 총 6 개의 가설 중 5 개 의 가설이 채택되었다. 요약해 보면 대형 유통

〈Table 5〉 Results of Multi-Group Analysis

\begin{tabular}{|c|c|c|c|c|c|c|c|c|c|}
\hline \multirow{2}{*}{$\begin{array}{l}\text { Hypo- } \\
\text { thesis }\end{array}$} & \multirow{2}{*}{ Path } & \multicolumn{3}{|c|}{$\begin{array}{l}\text { High ethical group } \\
\qquad(\mathrm{n}=108)\end{array}$} & \multicolumn{3}{|c|}{$\begin{array}{l}\text { Low ethical group } \\
(\mathrm{n}=104)\end{array}$} & \multirow{2}{*}{$\begin{array}{c}\text { Chin } \\
\text { statistics } \\
(t)\end{array}$} & \multirow{2}{*}{ Result } \\
\hline & & $\begin{array}{l}\text { Coeffi- } \\
\text { cient }\end{array}$ & $\begin{array}{l}\text { Standar } \\
\text { d error }\end{array}$ & t-value & $\begin{array}{l}\text { Coeffi- } \\
\text { cient }\end{array}$ & $\begin{array}{l}\text { Standard } \\
\text { error }\end{array}$ & t-value & & \\
\hline $\mathrm{H} 6$ & $\begin{array}{c}\text { Supply chain } \\
\text { leadership } \rightarrow \\
\text { Financial performance }\end{array}$ & 0.644 & 0.058 & 10.953 & 0.447 & 0.072 & 6.132 & $2.121^{*}$ & $\begin{array}{l}\text { Suppor } \\
\text { ted }\end{array}$ \\
\hline
\end{tabular}

$* \mathrm{p}<.05$

1) $t=\frac{\text { Path }_{\text {sample_1 }_{1}-\text { Path }_{\text {sample_2 }_{2} 2}}}{\sqrt{S \cdot E_{\text {samplel }}^{2}+S \cdot E_{\text {samplez }^{2}}^{2}}}$ 
업체의 관계적 행동 중 교육훈련, 공정한 보상, 조직 간 의사소통은 공급체인 리더십을 강화하 였고, 공급체인 리더십은 중소 공급업체의 재무 성과를 강화하는 것으로 나타났다.

한편 대형 유통업체의 윤리성은 조절효과를 가졌다. 다시 말해, 유통업체의 윤리성이 높은 경우가 그렇지 않은 경우에 비해 공급체인 리 더십의 효과가 더 강하게 나타났다. 이는 리더 가 비윤리적인 경우 공급체인 리더십의 효과를 약화시킨다는 것을 의미한다.

대부분의 가설들이 사전에 예상했던 대로 채 택되었지만 대형 유통업체의 비전 제시가 공급 체인 리더십을 강화하지 않는 것으로 나타나 가설 4 는 기각되었다. 그 이유를 추측해 보면 다음과 같다.

먼저 국내 편의점 업체들이 중소 공급업체들 에 대해 비전제시를 제대로 하고 있지 않은 것 아닌가 추측해 볼 수 있다. 실제로 공급업체들 이 응답한 비전제시 측정문항들의 평균을 구해 본 결과 5점 척도에서 3.49점을 보여 보통보다 조금 나은 수준으로 인식하고 있었다. 뿐만 아 니라 공급업체 납품담당자와의 심층면접을 해 보았을 때도 국내 편의점 업체들이 상생(相生) 에 대한 마인드 부족을 애로사항으로 느끼고 있었다.

다음으로 비전제시도 리더 윤리성의 조절효과 를 가지는 것이 아닌가 추측해 볼 수 있다. 실 제로 가설검정에는 포함되지 않았지만 비전제 시와 공급체인 리더십 간 관계에서 리더 윤리 성의 조절효과를 검정한 결과 $\mathrm{t}=2.11$ 로 나타났 다. 다시 말해 조절효과를 가진다는 것이다. 이 는 리더가 윤리적인 경우 리더의 비전제시가 리더십을 강화하지만, 비윤리적일 경우 비전제
시에 대한 저의를 의심하거나 “또 다른 통제" 로 여길 가능성이 있다.

요컨대 가설 4 가 기각된 것은 국내 편의점업 체들이 제대로 된 비전제시를 하지 못하고 있 는 측면과 함께 윤리성이 뒷받침되지 못하는 측면이 동시에 작용한 것으로 판단된다.

\section{2 연구의 공헌 및 경영학적 함의}

\subsection{1 이론적 공헌}

먼저 본 연구의 공헌은 이론적 공헌과 실무적 공헌으로 나누어 볼 수 있다. 먼저 이론적 공헌 은 첫째, 기존 공급체인 분야 연구에서 거의 다 루어지지 않았던 공급체인 리더십의 메커니즘 에 대해 실증하였다는 점이다. 이는 조직행동 분야에서 주로 연구되었던 리더십의 연구영역 을 조직 간 관계로 확대하고, 공급체인 관계에 적용했다는 의미를 지니고 있다.

둘째, 본 연구는 공급체인 리더십의 형성 요 인으로 관계적 행동 요인들의 영향관계를 규명 하였다. 이는 최근 기업 경영의 주요 관심사인 관계적 행동이 리더십의 선행요인이 될 수 있 다는 점에서 리더십 관련 향후 연구들에 중요 한 기초를 제공할 수 있다.

셋째, 본 연구는 공급체인 리더십과 팔로워의 재무성과 간 관계를 규명하고, 리더의 윤리성이 조절효과를 가짐을 규명하였다. 이는 리더십과 윤리성, 그리고 성과 간의 메커니즘을 이해하는 데 도움이 된다.

마지막으로 본 연구는 기존 연구들에서 거의 다루어지지 않았던 대형 유통업체와 중소 공급 업체 간 관계를 다루었다. 특히, 편의점 공급체 
인에 대해 다루었다. 이는 대형 유통업체와 중 소 공급업체 간에 발생하는 거래 파트너 간 관 계에 관한 이해를 증진시키는 데 도움을 줄 수 있고, 편의점 공급체인을 이해하는 데도 함의를 제공할 수 있다.

\subsection{2 실무적 공헌 및 경영학적 함의}

다음으로 실무적 공헌으로는 첫째, 대형 유통 업체가 중소 공급업체에게 공급체인 리더십을 가지기 위해 필요한 가이드라인을 제시하고 있 다. 특히, 국내 대형 유통업체들이 중소 공급업 체와의 관계에서 불공정거래 논란이 자주 일고, 거래상의 우월적 지위를 남용하는 사례가 빈번 한데, 본 연구의 결과는 이러한 대형 유통업체 의 행동들이 바람직하지 않다는 것을 보여주고 있다. 대형 유통업체들이 리더십을 가지기 위해 서는 교육훈련, 공정한 보상, 조직 간 의사소통 등의 관계적 행동을 충실히 이행하는 것이 바 람직하다고 할 수 있다.

둘째, 국내 대형 유통업체들의 리더십이 공급 업체의 재무성과를 강화한다는 점을 밝혔다. 이 는 최근 강조되고 있는 대기업과 중소기업 간 상생(相生)에 중요한 함의를 제공한다. 단순히 대기업이 중소기업과 초과이익을 공유하는 형 태는 지극히 단기적이고, 양쪽 모두가 만족할만 한 이익 공유 수준을 찾기 어렵다. 하지만 관계 적 행동을 통한 리더십 발휘가 상생의 또 다른 대안이 될 수도 있을 것이다.

셋째, 공급체인의 리더는 윤리성이 담보가 되 어야 한다는 점을 밝혔다. 본 연구에서는 윤리 성이 강한 리더의 경우가 비윤리적인 리더의 경우 보다 공급체인 리더십의 효과가 더 크게
나타났다. 이는 바꿔 말하면 비윤리적인 리더가 공급체인 리더십의 효과를 약화시킨다는 것을 의미한다. 특히, 대형 유통업체의 우월적 지위 남용이 현실인 국내 유통산업에서는 리더의 윤 리성에 대한 진지한 고민과 반성이 선행되는 것이 필요하다고 할 수 있다.

마지막으로 국내 편의점업체들이 적절한 비전 제시를 하지 못하고 있으며, 윤리성이 담보되지 않고 있다는 점을 연구결과를 통해 추론하였다. 비전 제시는 변혁적 리더십의 형태로 나타나서 궁극적으로 팔로워의 경쟁력을 강화시키는 역 할을 한다. 따라서 소위 말하는 “갑을관계”로 공급업체를 대하기 보다는 공급업체 상황에 맞 는 비전을 제시하고, 서로 발전해 나가는 관계 를 구축하고자 노력하는 것이 필요하다 할 수 있다.

\section{3 연구의 한계 및 향후 연구방향}

본 연구는 다음과 같은 연구의 한계를 가지고 있다. 첫째, 공급체인 리더십에 대한 보다 포괄 적인 연구설계가 필요하다. 본 연구는 공급체인 리더십의 선행요인으로 관계적 행동 요인들을 제시하였다. 하지만 이는 공급체인 리더십 형성 과정의 지극히 일부만을 설명한다고 할 수 있 다. 이론적, 실무적으로 개연성이 높은 선행변 수들이 더 있을 수 있다. 예를 들면, 리더의 개 성도 생각해 볼 수 있고, 본 연구에서 조절변수 로 다루었던 윤리성도 생각해 볼 수 있다.

둘째, 본 연구에서는 공급체인의 후방경로 리 더십에 대해 다루었다. 하지만 전방경로 즉, 유 통업체에 대한 리더십도 중요하다. 특히, 본 연 구의 대상산업인 편의점 본부의 경우 편의점 
가맹점들을 대상으로도 리더십을 가질 수 있다. 향후 공급체인의 전방경로 리더십에 대한 연구 가 보강될 필요가 있다.

셋째, 거래 파트너 간 힘-의존 관계를 고려한 연구설계가 필요하다. 본 연구는 일반적으로 편 의점 본부가 강한 힘을 가지고, 공급업체가 약 한 힘을 가지고 있는 힘의 구조 하에서 연구가 수행되었기 때문에 리더십의 복잡한 메커니즘 을 이해하는데, 어느 정도 한계를 가지고 있다. 향후 충분한 표본 수를 확보하거나 보다 정교 한 연구설계를 통해 대등한 힘을 가진 관계, 공 급업체가 우월한 힘을 가진 관계 하에서 공급 체인 리더십에 대한 연구도 필요할 것이다.

마지막으로, 편의점 공급체인만을 다루었다는 점이다. 본 연구는 서두에 밝혔듯이 리더십의 형성과정을 가장 잘 설명할 수 있는 공급체인 으로 편의점 공급체인을 선택하여 연구하였다. 하지만 대형 제조업체와 중소 공급업체 간 관 계, 대형 제조업체와 중소형 유통업체 간 관계, 편의점 이외의 유통업체와 공급업체 간 관계에 따라 다른 결과가 나타날 수도 있다. 향후 보다 많은 연구 설정 하에서 연구가 보강되어야 할 것이다. 이는 본 연구의 일반화 가능성도 높일 수 있다.

〈논문 접수일: 2011. 07. 05〉

〈1차 수정일: 2011. 08. 20〉

〈2차 수정일: 2011. 10. 17〉

〈게재 확정일: 2011. 10. 18〉

\section{참고문헌}

김상덕(2011), "프랜차이즈 본부의 리더십이 가 맹점의 조직동일시, 조직시민행동, 그리고 수익성에 미치는 영향: 조직 냉소주의의 조 절효과," 마케팅논집, 19(1), 1-27.

김상덕, 정연승(2008), “비대칭적 의존구조는 언 제나 관계의 질을 약화시키는가? 커뮤니케 이션의 역할," 서비스경영학회지, 9(2), 81-111. 오세조, 박진용, 김상덕(2009), 소비자지향적 유 통관리, 박영사.

장석인(2009), "변혁적 및 거래적 리더십이 조직 몰입에 미치는 영향에 관한 구조모형분석," 인적자원관리연구, 16(2), 213 229.

정대용, 이세호(2008), "LMX의 질을 매개로 팔 로워가 인지하는 리더의 지원과 갈등이 만 족, 영역초월행동, 그리고 재계약의도에 미 치는 영향 -프랜차이즈시스템의 생산성 중 심으로-” 생산성논집, 22(2), 211-239.

Anderson, James C. and David W. Gerbing (1988), "Structural Equation Model in Practice: A Review and Recommended Twostep Approach," Psychological Bulletin, 103 (2), 411-423.

Bagozzi, Richard P., and Yi, Youjae(1988), “On the Evaluation of Structural Equation Models," Journal of the Academy of Marketing Science, 16(1), 74-94.

Ballantyne, David(2000), "Reframing Internal Marketing for Relationship Marketing," Proceedings of the AMA International Marketing Educators' Conference: Marketing 
in a Global Economy, Buenos Aires, Argentina, June28-July1, 1-12.

Barnett, Timothy R. and Danny R. Arnold (1989), "Justification and Application of Path-Goal Contingency Leadership Theory to Marketing Channel Leadership," Journal of Business Research, 19, 283-292.

Bass, Bernard M.(1985), Leadership and Performance beyond Expectations, New York: Free Press.

Bass, Bernard M. and Bruce J. Avolio(1990), "The Implications of Transactional and Transformational Leadership for Individual, Team, and Organizational Development," Research in Organizational Change and Development, 4, 231-272.

Bass, Bernard M. and Bruce J. Avolio(1997), Full Range of Leadership: Manual for the Multi-factor Leadership Questionnaire, Palto Alto, Ca: Mind Garden.

Bercovitz, Janet, Sandy D. Jap, and Jack A. Nickerson(2006),"The Antecedents and Performance Implications of Cooperative Exchange Norms," Organization Science, 17 (6), 724-740.

Berry, Leonard L.(1999), Discovering the Soul of Service: The Nine Drivers of Sustainable Business Success, New York: Free Press.

Blau, Peter M.(1964), Exchange and Power in Social Life, New York: Wiley.

Boomer, William H., Robert S. Rubin, and Timothy T. Baldwin(2004), "Setting the
Stage for Effective Leadership: Antecedents of Transformational Leadership Behavior," The Leadership Quarterly, 15, 195-210. Brown, Michael E. and Linda K. Trevino(2006), "Ethical Leadership: A Review and Future Directions," Leadership Quarterly, 17, 595-616.

Brown, Michael E. and Linda K. Trevino, and David A. Harrison(2005), "Ethical Leadership: A Social Learning Perspective for Construct Development and Testing," Organizational Behavior and Human Decision Processes, 97, 117-134.

Brown, Michael E. and Marie S. Mitchell (2010), "Ethical and Unethical Leadership: Exploring New Avenues for Future Research," Business Ethics Quarterly, 20(4), 583-616.

Carmeli, Abraham, Gershon Gilat, and David A. Waldman(2007), "The Role of Perceived Organizational Performance in Organizational Identification, Adjustment and Job Performance," Journal of Management Studies, 44(6), 972-992.

Chin, Wynne W.(2000), http://disc-nt.cba.uh. edu/chin/plsfaq.htm.

Chin, Wynne W.(2004), PLS-Graph User's Guide, University of Houston Press.

Ciulla, Joanne. B.(Ed.) (2004), Ethics, the Heart of Leadership(2nd ed.) Westport, CT: Praeger.

Congram, Carole A. and Margaret L. Friedman (1991), “The Quality-leadership Connection 
in Service Business," In C. Congram(Ed.), Handbook of Marketing for the Service Industries(pp. 3-19). New York: American Management Association.

Coughlan, Anne T., Erin Anderson, Louis W. Stern, and Adel I. El-Ansary(2006), Marketing Channels, Prentice Hall, 6th ed.

Doyle, Jim(2010), “An Investigation of Pricing Data for Evidence of Institutional-Level Relationship Marketing Behaviors," Journal of Relationship Marketing, 9(4), 264-278.

Dukerich, Janet M., Brian R. Golden, and Stephen M. Shortell(2002), "Beauty is in the Eye of the Beholder: The Impact of Organizational Identification, Identity and Image on the Cooperative Behaviors of Physicians," Administrative Science Quarterly, 47, 507-533.

Dwyer, F. Robert, Paul Schurr, and Sejo Oh (1987), "Developing Buyer-Seller Relationships," Journal of Marketing, 51(2), 11-27. English, Wilke D. and Donald A. Michie(1985), "The Impact of Electronic Technology Upon the Marketing Channel," Journal of the Academy of Marketing Science, 13(2), 57-71.

Etgar, Michael(1977), "Channel Environment and Channel Leadership," Journal of Marketing Research, 14(1), 69-76.

Falk, R. Frank and Nancy B. Miller(1992), A Primer for Soft Modeling, University of Akron Press.

Fehr, Ernst and Simon Gachter(2000), "Fairness and Retaliation: The Economics of Reciprocity," Journal of Economic Perspectives, 14(3), 159-181.

Ferguson, Ronald J., Michele Paulin, and Jasmin Bergeron(2005), "Contractual Governance, Relational Governance, and the Performance of Interfirm Service Exchanges: The Influence of Boundary Spanner Closeness," Journal of the Academy of Marketing Science, 33(2), 217-234.

Foreman, Susan K. and Arthur H. Money(1995), "Internal Marketing: Concepts, Measurement, and Application," Journal of Marketing Management, 11(8), 755-768.

Forrester, Russ(2000), “Empowerment: Rejuvenating a Potent Idea," Academy of $\mathrm{Ma}^{-}$ nagement Executive, 14(3), 67-80.

Frazier, Gary L.(1983), "Interorganizational Exchange Behavior in Channels of Distribution: A Broadened Perspective," Journal of Marketing, 47(4), 68-78.

Frazier, Gary L. and Jagdish N. Sheth(1985), "An Attitude-Behavior Framework for Distribution Channel Management," Journal fo Marketing, 49(3), 38-48.

Gronroos, Christian(1982), Strategic Management and Marketing in the Service Sector, Swedish School of Economics and Business Administration(Helsingfors).

Harrigan, Kathryn R.(1988), "Partner Asymmetries," In Cooperative Strategies in International Business. Contractor, Farok J. and Peter Lorange(eds.), Lexington, MA: 
Lexington Books.

Hewett, Kelly and William O. Bearden(2001), "Dependence, Trust, and Relational Behavior on the Part of Foreign Subsidiary Marketing Operations: Implications for Managing Global Marketing Operations," Journal of Marketing, 65(3), 51-66.

Hibbard, Jonathan D., Nirmalya Kumar, and Louis W. Stern(2001), "Examining the Impact of Destructive Acts in Marketing Channel Relationships," Journal of Marketing Research, 38(1), 45-61.

Hoppner, Jessica J. and David A. Griffith(2011), "The Role of Reciprocity in Clarifying the Performance Payoff of Relational Behavior," Journal of Marketing Research, 48(5), 920-928.

Hult, G. Thomas M.(1997), “A Study of Global Team Vision in the Internal Marketing System," AMA Winter Educators' Conference Proceedings, 8, 22-22.

Hult, G. Tomas M., O. C. Ferrell, Robert F. Hurley, and Larry C. Giunipero(2000), "Leadership and Relationship Commitment," Industrial Marketing Management, 29, 111119.

Ivens, Bjoern S. and Keith J. Blois(2004), "Relational Exchange Norms in Marketing: A Critical Review of Macneil's Contributions," Marketing Theory, 4(3), 239-263.

Jap, Sandy(1999), "Pie-Expansion Efforts: Collaboration Processes in Buyer-Seller Relationships," Journal of Marketing Research,
36(4), 461-475.

Jap, Sandy and Erin Anderson(2007), “Testing a Life-Cycle Theroy of Cooperative Interorganizational Relationships: Movement Across Stages and Performance," Management Science, 53(2), 260-275.

Kelemen, Mihaela and Ioanna Papasolomou(2007), "Internal Marketing: A Qualitative Study of Culture Change in the UK Banking Sector," Journal of Marketing Management, 23(7-8), 745-767.

Kime, Charles H.(2001), Organizational Leadership: Fire Service in the United States, JAI, Elsevier Science.

Klimoski, Richard J., and Noreen J. Hayes(1980), "Leader Behavior and Subordinate Motivation," Personnel Psychology, 33, 543-564. Lipset, S. M. (1975), "Social Structure and Social Change," in Approaches to the Study of Social Structure, Peter M. Bleu, ed., New York: The Free Press.

Lusch, Robert F. and James R. Brown (1996), "Interdependency, Contracting, and Relational Behavior in Marketing Channels," Journal of Marketing, 60 (October), 19-38. Mayer, David M., Maribeth Kuenzi, Rebecca Greenbaum, Mary Bardes, and Rommel Salvador(2009), "How Low Does Ethical Leadership Flow? Test of a Trickle-down Model," Organizational Behavior and Human Decision Processes, 108, 1-13.

Mehta, Rajiv(2000), "Impact of Leadership Style on Channel Partner Motivation: An Em- 
pirical Test," Journal of Marketing Channels, 7(3), 121-153.

Mohr, Jakki and John R. Nevin(1990), "Communication Strategies in Marketing Channels: A Theoretical Perspective," Journal of Marketing, 54(4), 36-51.

Morgan, Gareth(1986), Images of Organization, Sage Publications. California.

Morgan, Robert M., and Shelby D. Hunt(1994), "The Commitment-Trust Theory of Relationship Marketing," Journal of Marketing, 58(3), 20-38.

Neubert, Mitchell J., Dawn S. Carlson, K. Michele Kacmar, James A. Roberts, and Lawrence B. Chonko(2009), "The Virtuous Influence of Ethical Leadership Behavior: Evidence From the Field," Journal of Business Ethics, 90(2), 157-170.

Nunnally, Jum C. and Bernstein, Ira(1994). Psychometric Theory, 3rd ed., New York: McGraw Hill.

Ooncharoen, Nantana and Phapruke Ussahawanitchakit (2009), International Journal of Business Research, 10(1), 24-30.

Pelham, Alfred M. and David T. Wilson(1996), "A Longitudinal Study of the Impact of Market Structure, Firm Structure, Strategy, and Market Orientation Culture on Dimensions of Small-Firm Performance," Journal of the Academy of Marketing Science, 24 (1), 27-43.

Price, Retha A.(1991), "An Investigation of Path-Goal Leadership Theory in Marketing
Channels," Journal of Retailing, 67(3), 339361.

Price, Retha A.(1993), "Effects of Channel Leadership Behaviours under Different Levels of Channel Member Interdependence," International Review of Retail, Distribution \& Consumer Research, 3(3), 261-278.

Rafiq, Mohammed and Pervaiz K. Ahmed (2000), "Advances in the Internal marketing Concept: Definition, Synthesis, and Extension," Journal of Services Marketing, 14(6), 449-462.

Schul, Patrick L, William M. Pride, and Taylor L. Little(1983), "The Impact of Channel Leadership Behavior on Intrachannel Conflict," Journal of Marketing, 47(3), 21-34.

Shiu, Yung-Ming and Tsu-Wei Yu(2011), "Internal Marketing, Organisational Culture, Job Satisfaction, and Organisational Performance in Non-life Insurance," The Service Industries Journal, 30(6), 793-809.

Siguaw, Judy A., Penny M. Simpson, and Thomas L. Baker(1998), "Effects of Supplier Market Orientation on Distributor Market Orientation and the Channel Relationship: The Distributor Perspective," Journal of Marketing, 62(3), 99-111.

Tax, Stephen S. and Stephen W. Brown (1998), "Recovering and Learning From Service Failures," Sloan Management Review, 39(3), 75-88.

Toor, Shamas-ur-Rehman and George Ofori (2009), “Ethical Leadership: Examining 
the Relationships with Full Range Leadership Model, Employee Outcomes, and Organizational Culture," Journal of Business Ethics, 90, 533-547.

Trevino, Linda K., Laura Hartman, and Michael Brown(2000), "Moral Person and Moral Manager: How Executives Develop a $\mathrm{Re}^{-}$ putation for Ethical Leadership," California Management Review, 42(4), 128-142.

Trevino, Linda K., Michael Brown, and Laura P. Hartman(2003), “A Qualitative Investigation of Perceived Executive Ethical Leadership: Perceptions from Inside and Outside the Executive Suite," Human Relations, 55, 5-37.

Ullrich, Johannes, Jan Wieseke, Oliver Christ, Martin Schulze, and Rolf van Dick(2007), "The Identity-Matching Principle: Corporate and Organizational Identification in a Franchising System," British Journal of Management, 18, 29-44.

Vandaele, Darline, Deva Rangarajan, Paul Gemmel, and Annouk Lievens(1007), "How to Govern Business Services Exchanges: Contractual and Relational Issues," International Journal of Management Review, 9(3), 237-258.
Walumbwa, Fred O., Schaubroeck J.(2009), "Leader Personality Traits and Employee Voice Behavior: Mediating Roles of Ethical Leadership and Work Group Psychological Safety," Journal fo Applied Psychology, 94, 1,275-1,286.

Yueh, Li, Andy Chen, Ying Lee, and F. Barry Barnes(2010), “The Effects of Leadership Styles on Knowledge-based Customer $\mathrm{Re}^{-}$ lationship Management Implementation," International Journal of Management and Marketing Research, 3(1), 1-18.

Zhang, Chun, S. Tamer Cavusgil, and Anthony S. Roath(2003), "Manufacturer Governance of Foreign Distributor Relationships: Do Relational Norms Enhance Competitiveness in the Export Market?" Journal of International Business Studies, 34(6), 550-566.

Zhu, Weichun, Douglas R. May, and Bruce J. Avolio(2004), "The Impact of Ethical Leadership Behavior on Employee Outcomes: The Roles of Psychological Empowerment and Authenticity," Journal of Leadership \& Organizational Studies, 11(1), 16-26. 


\section{〈부록〉측정문항}

교육훈련 $(\mathrm{a}=.857)$

1. 업체의 신제품 개발 교육이 좋다.

2. 업체는 우리의 사업을 전반적으로 향상시키는데 필요한 프로그램을 만든다.

3. 업체의 전반적인 교육지원이 좋다.

공정한 보상 $(\mathrm{a}=.952)$

1. 우리의 수고와 노력에 비교해 볼 때, 업체와의 거래에서 얻는 이익은 공정하다.

2. 동종업계와 비교해 볼 때, 업체와의 거래에서 얻은 혜택은 공정하다.

3. 업체의 수익과 비교해 볼 때, 우리의 이익과 혜택은 공정하다.

4. 덥체의 마케팅활동에 비교해 볼 때, 우리의 이익과 혜택은 공정하다.

비전제시 $(\mathrm{a}=.851)$

1. 업체는 우리가 그들이 권유하는 일을 했을 때 기대되는 좋은 점에 대한 청사진을 보여준다.

2. 업체는 우리가 그들의 요청에 따랐을 때의 좋은 결과를 제시한다.

3. 업체는 우리가 그들의 조언에 따랐을 때 금전적으로 성공할 수 있다고 제안한다.

조직 간 의사소통 $(\mathrm{a}=.869)$

1. 우리와 업체는 사업의 이익과 성장기회에 대해 같이 토의한다.

2. 우리와 업체는 다른 업체들에게 말하지 못할 것들도 서로 이야기한다.

3. 우리와 업체는 서로에게 솔직히 말한다.

4. 우리와 업체는 서로에게 시기적절한 정보를 제공한다.

5 . 업체의 담당자와 문제가 생기면, 우리는 그 담당자에게 그것에 대해 말할 것이다.

6. 업체의 담당자는 정보 요구에 바로 응한다.

공급체인 리더십 $(a=.933)$

1. 업체는 거래관계에서 우리에게 무엇을 기대하고 있는지 알려준다.

2.— 업체는 거래관계에서 일관성 있는 절차를 따르도록 권장한다.

3. 업체는 거래관계에서 무엇이 필요하고, 어떻게 할 수 있는지 결정한다.

4. 업체는 성과의 기준(표준)을 결정한다.

5. 업체는 거래관계에서 이기적인 관심을 주장하지 않는다.

6.—입체는 우리의 이익에 관심을 가진다.

7. 업체는 우리에게 조언을 해 주거나 교육해 주는데 시간을 쓴다.

8. 업체는 거래관계에서 문제가 발생했을 때 다양한 의견을 듣고자 한다.

9. 업체는 우리 업무의 핵심적인 목표에 대해 명확하게 알려준다.

재무성과 $(a=.943)$

1._업체와의 거래로 인해 시장점유율이 높아졌다.

2. 업체와의 거래로 인해 시장점유율 증가 추이가 좋아졌다.

3.—업체와의 거래로 인해 수익성이 좋아졌다.

4. 업체와의 거래로 인해 수익성의 증가 추이가 좋아졌다. 


\title{
The Effects of Relational Behaviors on Supply Chain Leadership and Financial Performance: The Role of Leader Ethicality
}

\author{
Kim, Sang Deok*
}

\begin{abstract}
After more than 25 years of accumulated research evidence, there is little doubt that leadership behavior is related to a wide variety of positive individual and organizational outcomes. Indeed, leadership behavior has been empirically linked to increased employee satisfaction, organizational commitment, extra effort, turnover intention, organizational citizenship behavior, and overall employee performance.

However, it is important to point out that although leadership behavior has been linked to a number of positive organizational outcomes, research regarding the antecedents of such behavior is limited. Especially there is little research dealing with the antecedents of inter-organizational leadership behavior.

Supply chain leadership can be defined as the activities undertaken by the supply chain leader to influence the management programs and strategies of supply chain members. Supply chain performance is influenced by leadership of supply chain leader.

Although research on supply chain leadership can be broadly categorized, many researchers have been preoccupied with analyzing supply chain leadership by the power-influence approach measuring such as control, power, and power bases. Also they have not examined the relationship between leadership and financial performance. This study has started to overcome those research gaps.

The purpose of this study is to investigate the effect of relational behaviors on supply chain leadership, and the effect of such leadership behavior on financial performance of supply chain followers. In addition, this study also try to find out moderating variable existing in the relationship.

To be concrete, First, this study develops a model of the antecedents of four conceptually distinct forms of relational behaviors such as training, fair reward, offering vision, and inter-organizational communication, and tests the hypothesized differential effects of relational behavior forms on supply chain leadership. Second, this study tests the effect of supply chain leadership on financial performance.
\end{abstract}

\footnotetext{
* Associate Professor, Department of Business Administration, Kyungnam University
} 
Third, this study investigates the extent to which this leadership-performance relationship is moderated by leader ethicality.

The reason why this study deals with convenience store supply chain is that there is very strong inter-dependence between a franchisor and its suppliers. Their strong inter-dependence makes their relationship as the relationship between a superior and subordinates and creates an atmosphere that leadership occur without difficulty.

For the purpose of empirical testing, 217 respondents of suppliers of convenience store supply chain in Korea were surveyed and the analysis utilizing partial least square model indicated that training, fair reward, inter-organizational communication had positive effects on supply chain leadership, and such leadership had positive effect on financial performance of followers. On the other hand, offering vision had no effect on supply chain leadership.

In addition, leader ethicality had moderating effect on the relationship between supply chain leadership and financial performance.

Key words: Supply chain leadership, Inter-organizational leadership, Relational behavior, Financial performance, Leader ethicality 